\title{
The Application of Corpus in Spoken English Learning of Non-English Major College Students
}

\author{
Xiaowei $\mathrm{Li}^{\mathrm{a}}$ \\ School of Foreign Languages, Southwest Petroleum University, Chengdu, China \\ a1195495274@qq.com
}

\begin{abstract}
Keywords: Chinese Learner English Corpus (CLEC), National English Corpus (BNC), Non-English Major College Students; Spoken English Learning.
\end{abstract}

\begin{abstract}
Based on Chinese Learner English Corpus (CLEC) and National English Corpus (BNC), combined with spoken English learning situation of non-English major college students and the characteristics of corpus itself, this thesis employs the combination of qualitative and quantitative research approaches, aiming to illustrate that the corpus can play a big role in non-English majors' spoken English learning, to cause enough attention and actively use corpus to improve spoken English level.
\end{abstract}

\section{Introduction}

With the further deepening of economic globalization, international communication and cooperation are more urgent and close than any time in history, and English as a global language, whose applied range is the widest. English study and research in China get rapid development, gradually improve the English study and research methods, but this is not happen overnight, and even some method needs to be improved and perfected. With the rapid progress in science and technology, some new innovative research perspectives need to be explored further.

When Chinese people learning English often have "Chinglish" phenomenon, namely sometimes Chinese expression with strong Chinese thinking patterns, it is not in conformity with the English expression habits and thinking ways, which makes English communication to be barriers, it is not conducive to cooperation and communication in economic, political and cultural aspects.

Though English received extensive attention in domestic, many universities have set up English majors, courses of English aspects, even science major, English is also the compulsory course, but students' gain in English are not satisfactory, this high investment, low efficiency or low quality output, which make we have to find a way out to further improve my English.

Our English education attach great importance to the English input and ignore the output for a long time, although now freshman and sophomore period of English majors add the spoken English class, but it does not to be sustained, the students' spoken English decline again, not to mention the non-English major students, their English learning mainly introduces related professional knowledge, spoken English is basically ignored. More importantly he/they are influenced by the traditional English teaching, English speaking ability is poor and make students ignorant and at a loss, "drowning man will catch at a straw" is often a waste of time, energy and money.

Five corpus of core journals and its application research are surveyed during 2008-2012, the author found that corpus research become refined, and found in 100 research papers, including the five research content: ontology research of corpus are 18 papers, the percentage is $18 \%$; research of classroom teaching based on corpus are 9 papers, the percentage is $9 \%$; vocabulary research based on corpus are 9 papers, the percentage is 9\%; research of spoken English based on corpus are 10 papers, the percentage is $10 \%$. In recent years, the corpus are used in classroom teaching and corpus vocabulary research are rapidly increased, and spoken English research based on the corpus does not break through the traditional research content, so research in this aspect needs to be improved. In addition, when searching CNKI, Wanfang data, it is easily find current domestic spoken English corpus research mainly focuses on some language phenomenon analysis, foreign language teaching, 
etc., and domestic spoken English from the point of the research object, research on English major students' spoken English research is more than non-English major students' spoken English research; From the point of the research content, the expressive effect of spoken English, spoken English teaching, the spoken language test research are more, but the process of spoken expression, context research are less.

Based on these big international environment demands for English, the English learning situation of domestic students, and the domestic current research situation based on corpus, the author thinks that the exploration of improving spoken English method and spoken English research should be diversified. The corpus as an emerging subject, the collected and stored real language materials as the research object, it can provides a new thinking for college spoken English research and hopes to open up a new path on learning and research of spoken English.

\section{The role of corpus on non-English major college students' spoken English learning}

Taking students as the center, use scientific methods to collect information, understand the lack or imbalance of student in spoken English learning, and seek to meet their countermeasure process of learning needs " learning needs analysis, not only can correct the deviation of the teachers' subjective speculation in English teaching, make spoken English teaching "targeted", but also benefit the concept of the students as subject, improve their spoken ability (Tian Haiyan, 2003:21). This research targets that there are still quite a number of non-English major college students' spoken English level is low at present, the "students as the center" guiding ideology, through more than 200 non-English major students' spoken English learning situation questionnaire (see the appendix) in Southwest Petroleum University, understand the learning situation of the non-English major students' spoken English, analyze the learners' spoken English learning situation, provide lessons for realizing a qualitative improve learners' spoken English. In order to understand non-English major students' learning situation, SPSS software is used to analyze the investigation, now select the three charts:

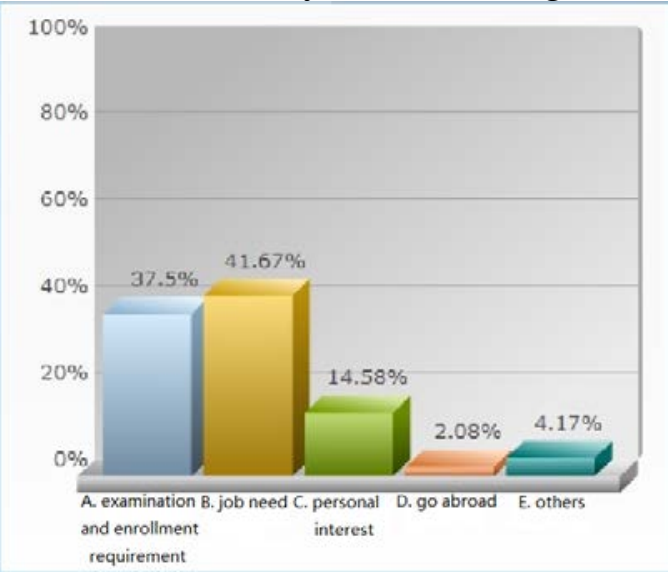

Fig.1 Spoken English learning goals of non-English major college students

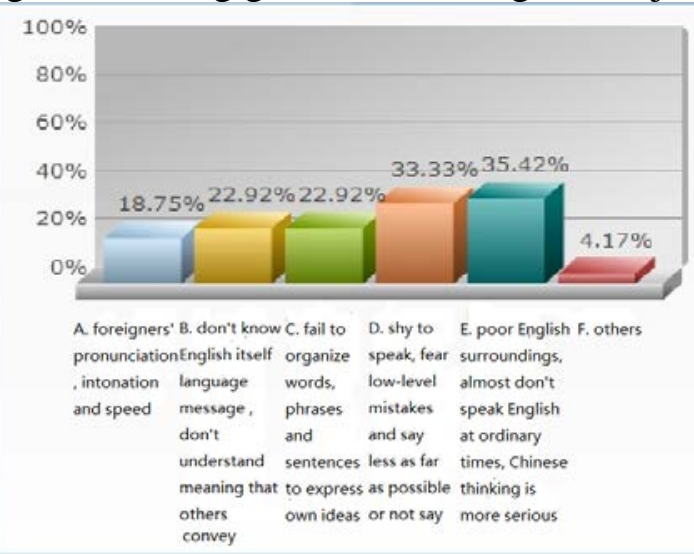

Fig.2 Spoken English learning disabilities of non-English major college students 


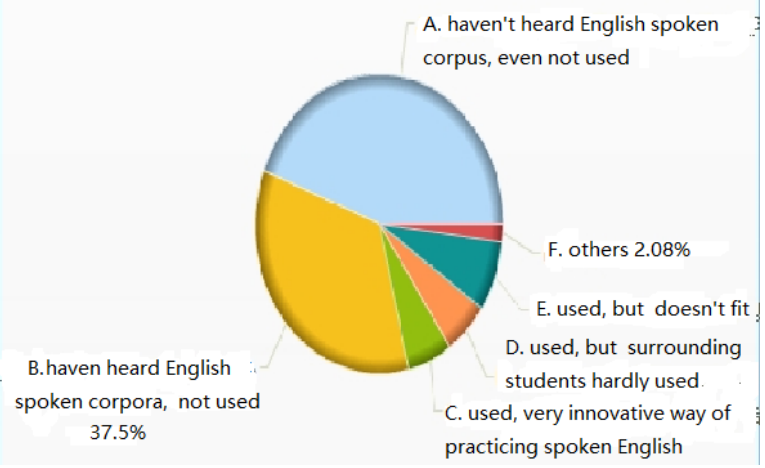

Fig.3 The condition that non-English major college students use spoken English corpus to learn English

From the above three figures, we can see that non-English major college students' spoken English learning features: in terms of English learning content, the spoken language is an essential part of learning English, spoken English level is more and more becoming an important indicator that measure the level of English, nowadays, there are all kinds of English class exam in society, and all have a spoken test, it can be seen that spoken English ability is becoming more and more important, but the whole of China students' spoken English is poor. Compared with English major students, more problems exist in the non-English major students in spoken English learning, first of all, no system to learn English, pronunciation and intonation of spoken English and spoken communication is basically rely on classroom learning, English communication is almost zero outside the classroom, freshman and sophomore have English course, some professional sophomore does not have courses related to English, especially spoken English learning is more and more not so important. Secondly, because non-English major students' learning is mainly used for major-related English expression, many of them are out of communication of the actual life, teaching goal and rarely involves the spoken practice, most are just some audio-visual audio, complete exercises of the book, this is basically the same as learning English pattern basic in times of middle school, it is difficult to improve spoken English. Thirdly, the non-English major students' learn English more intentionally, more is for test or employment, losing the continuity of learning spoken English, put spoken English behind them, naturally spoken "backward" phenomenon appear. Finally, non-English major students also face no greater English language learning environment this key problem, and influenced by mother tongue migration, the Chinese thinking is dominant, and to overcome these factors is the most effective way to learn spoken English well, a lot of research have also shown that move to the country, "immersive" learn spoken English, but let every Chinese that want to learn spoken English well go abroad is not realistic, but the spoken English corpus and corpus of English countries provides real spoken English communication material, make spoken English learners "immersive" indirectly, direct contact the real scene of spoken English, and communicate with English national, this is not available to idealized spoken communication mode in many teaching materials.

\subsection{The features and classification of the corpus}

There are three basic understanding on corpus: what appeared in the corpus are actual use of language in real language materials; corpus is basic resources take computer as the carrier and bear language knowledge; the real languages need to be processed (analyze and handle) and then could be a useful resource. Corpus is main resource of empirical language research method. Corpus is applied to lexicography, language teaching, and traditional language research, natural language processing based on statistical or instance research aspect. There are different types of corpus, according to the research purposes and application, which is divided into four kinds: (1) the heterogeneous: no specific corpus collection principle, widely collect and store all kinds of corpus and save original; (2) the homogeneous: only collect corpora with the same content; (3) the system: according to the predetermined principle and proportion collect corpora, make the corpus have balance and systematization, can represent language facts in certain range; (4) the special: only collect the corpus for particular purpose. According to the language of corpus, corpus can be divided into the monolingual, bilingual and multilingual. According to the acquisition unit of corpus, corpus can be 
divided into the discourse, statement, phrases. Among them, the bilingual and multilingual corpus in accordance with the organization form of corpus, they also can be divided into parallel (aligned) corpus and comparative corpus. This article is selected from British National Corpus; British National Corpus is one of the largest corpuses that can be directly used on the network, which is also currently the world's most representative one of the contemporary English corpuses. British National Corpus is jointly developed and established by Oxford University press, Longman Publishing Company, Oxford computer service center, English computer center IN Lancaster University, and the British library and so on, which is completed in 1994. The word capacities of British national corpus are more than one hundred million, which is constituted by 4124 modern British English text with wide representative. The written language account for $90 \%$, spoken language account for $10 \%$, non-English major college students can use to learn natural language and avoid Chinese expression. Chinese learner English corpus (CLEC) is the national social science fund Ninth Five-year plan project, corpus (CD) was published by Shanghai Foreign Language Education Press in 2003 (Gui Shichun, Yang Huizhong, 2003), this corpus collected Chinese middle school, college English 4, 6 class, junior and senior of English majors, more than 100 words, it is China's first corpus for tagging speech errors, its purpose is to observe all kinds of English features and language mistakes of students, after non-English major college students understanding these features and situation, can more enhance a mistake sense, avoid making the same mistake.

\subsection{Spoken English learning effect based on corpus}

Chinese students learn a foreign language, inevitably affected by negative transfer of mother tongue, and because the surrounding foreign spoken language learning environment, spoken English learning is divorced from "original soil", the students often cannot decide whether express naturally and puzzled. Spoken English corpus can serve as an effective complement of the textbooks and its role mainly focus on three points:

(1) Enriching the content of textbooks. From the perspective of the foreign language teaching, language output is established on the basis of language input, and quality and quantity of the input language is one of the important factors to improve spoken English, but spoken English corpus can provide rich and real corpus for non-English major college students for consulting and studying, for example, two corpuses that text advocates are used to combine, can learn about Chinese learning basic situation, clear own level, identify own spoken English status, and then use British National Corpus to obtain idiomatic expression, gradually overcome the Chinese thinking mode in English expression, form a good spoken English study habits.

(2) Help non-English major students faster and more effective achieve learning task or goal task. Through the corpus, the student can analyze, summarize the meaning of certain word and collocation rules in the context. In foreign language learning, language learners think collocation of language elements is relatively free, actually this kind of freedom in native language expression is very limited (Pawley\&Syder, 1983:1983). People are more and more aware of the importance of collocations in English teaching (Bahns 1993:1993). In our country, oral English learners always intentionally or unintentionally accumulated fixed collocation for later use, but it is difficult to extract in later use, the most common phenomenon is that conversation with foreign teachers can be not well organized in his own language, further can't express myself very well, the reason is when the learners accumulating lexical chunks are often out of chunk use context, but "dig" and rote, but is not very good "place" when using.

(3) Broaden the use scope of spoken English corpus and other English corpuses. Corpus is introduced into China since the 1980s, which is mainly used to study some language phenomenon, foreign language teaching and lexicography. In terms of spoken language, corpus mainly study effect of spoken language, spoken language and spoken language test, etc. Therefore corpus is mainly used in the research; it seems to be hard for average student to access, not to mention very good use, the above survey on non-English major students can be found that many students almost have never heard of it. This shows that corpus is used for minority; however, corpus can also play a more important role and applied to the study, which can make the students to do the masters of their own learning, their learning analysts, mediators, and gain more initiative in learning. 
(4) Help non-English major students better autonomously learn. Non-English major students' English courses is few, spoken language courses can be counted on one's fingers, so their spoken language learning is mainly for exam-oriented, enrollment, study abroad, interest, etc. However, many students independently learn spoken language relying on reciting segment far from English context, or idealized and patterned material. Spoken English corpus at this time is the best teacher; "immersive" realized and cannot go abroad. Only English idiomatic input can promote idiomatic expression, perhaps pronunciation and intonation are not standard than foreigners, but the ideas, views of exchange does not have many obstacles.

\section{Conclusion}

In recent years, corpus is more and more concerned and studied by linguists, education workers, and computer professionals and so on. The author believes that the use of corpus should not only stay in the research phase, ordinary scholars can also actively take the initiative to find the features of the corpus itself, that is rich, authentic, reliable corpus, the corpus is derived from the actual circumstances of the source language environment, it should be used to guide the learning itself. Non-English major college students' oral English learning has its features, the use of spoken English corpus can make them "immersive" learn oral English, input/output correctly, native English expression, gradually get rid of Chinese thinking, it is not only beneficial to students' promotion of English writing, translation and other comprehensive ability, and increase the interest in spoken English learning, self-confidence, get into the habit of good spoken English learning, and get rid of the embarrassment to speak and English spoken language learning anxiety condition.

\section{References}

[1] bahns, J.L1993,47(1):56-63.

[2] Gui Shichun, Yang Huizhong. Chinese Learner English Corpus [M]. Shanghai foreign language education press, 2003

[3] Pawley, A.\&Syder, F.H. Twopuzzles for linguis tictheory: native like selection and native like fluency [A].in Richards, J.C. and Schmidt, R.W.(eds.) Language and Communication, London: Longman, 1983.

[4] Tian Haiyan, students' learning needs analysis in the development of school curriculum [J], Management of primary and middle schools, 2003-12 P:21.

[5] http://www.yywz123.com/web/44301.html

[6]http://baike.baidu.com/link?url=XAtR258WOM29-qcLzm6OGNv1ZIK8xTQpJwqIFg1IFKHqH q2ANuepMzJgyZqNQov0GWCJLdC06KUbvL6z9uEGZK 